\title{
Massive aid mobilization needed in Darfur: MSF
}

Despite the WHO's declaration that the conflict in Sudan has resulted in the world's largest ongoing humanitarian emergency, aid is still desperately needed, says the president of Médecins Sans Frontières (MSF) Canada.

"There simply aren't enough resources to deal with the crisis," says Montréal pediatrician Dr. Joanne Liu, who returned Sept. 18 after 5 weeks in the Darfur Region of Western Sudan. "We can't even fulfill basic needs."

Many NGOs are waiting for funding and trying to handle logistical problems, such as long delays to obtain a visa, says Liu. "Rich countries in the world should contribute to alleviating the suffering of these people," she adds.

Up to 50000 people have been killed and more than 1.2 million people driven from their homes in more than a year of fighting between government forces and Darfur rebels. Some 120000 Sudanese have crossed into Chad, while an estimated 700000 people are living at 129 camps in Darfur.

These camps exceed the threshold of what constitutes a humanitarian crisis, says WHO, which defines a crisis as causing 1 death per 10000 people per day. WHO reports the crude mortality rate as 1.5 deaths per 10000 in North Darfur and 2.9 in West Darfur. In addition, $23.6 \%$ of internally displaced persons (IDPs) are malnourished. "Darfur needs more assistance," Dr. Lee JongWook, WHO's director-general, said Sept. 13.

The situation is getting worse, adds Liu. "People are still fleeing villages and fattening the camps, which are already over-capacity and under-resourced," she says. "We can't be indifferent to human suffering."

MSF began work in the Republic of Sudan in December 2003. About 205 international staff, including a dozen Canadians, and 2000 Sudanese employees work with more than
400000 IDPs at 26 of the camps.

MSF is providing medical and nutritional care, but current operations fall "dramatically short of the immense need. A massive mobilization of assistance is critical," says the organization's international office.

At Kalma, Darfur's largest camp, with 75000 people, 21 children die daily due to malnutrition, says Liu. Food distribution is sketchy, with delays due to logistical difficulties and security threats. Because of the delay, 200 more children under 5 began using MSF's nutritional feeding centre.

"Delaying food a week makes a huge difference in the number of patients. That's how fine the line is," said Liu. "This is objective data you cannot deny."

MSF opened a second nutritional feeding centre for severely malnourished children Aug. 28; the 2 centres now treat 900 children. WHO reports that pediatric malnutrition in the camps has reached as high as $30 \%$, with 1 in 10 children affected by severe malnutrition.

MSF also runs a supplemental feeding centre at Kalma for 4000 children under 5 years of age, and a primary health care outpatient unit where they treat numerous cases of diarrhea, upper respiratory tract infection and malaria. The unit began treating victims of gender-based violence in August, offering medical treatment and psychosocial support. "We don't know how big a problem it is," says Liu.

Water shortages compound the problem. People only recently began receiving the minimum requirement of 5 litres of water a day (normal requirements are 15-20 L/day). There have been 2 disease outbreaks: shigellosis and hepatitis E. As of Aug. 20, WHO reported 2432 cases of the latter, with 41 deaths, up from 625 cases and 22 deaths between May and July.

Kalma is now preparing for cholera, which has already struck camps in neighbouring
Chad. So far, Chad camps report 2000 cases of cholera and 100 deaths. If cholera hits the Darfur camps, Liu anticipates it could spread quickly.

"It would be a major catastrophe," says Liu, who has worked with MSF for 9 years.

Liu also worked at the camp in Kass City, some $70 \mathrm{~km}$ from Kalma, where 45000 IDPs live. The nutritional feeding centre there serves 400 children, and the supplementary feeding centre has 2000 clients.

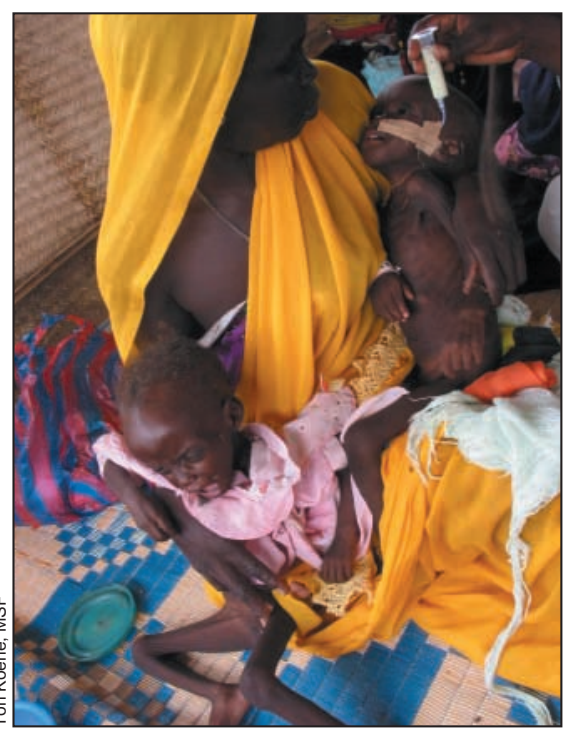

Up to $30 \%$ of childen in Darfur camps are undernourished.

The 2 camps have had a "fair amount" of hepatitis E, some 25-60 cases per week, says Liu.

Despite the seemingly overwhelming situation in the camps, there has been progress. For instance, 2.1 million children in Darfur have been vaccinated against measles, and WHO reports that 700000 IDPs now have access to clean water.

Once Sudan becomes more stable, Liu says the country will still need support. "We have to commit for 9 months to achieve food security and rebuild the civilian administration, such as hospitals," she says. "We're not even close to that. We'll be here another year, minimum." Barbara Sibbald, CMAJ 